\title{
Phase Polymorphism, Molecular Motions and Structural Changes in $\left[\mathrm{Cr}\left(\mathrm{NH}_{3}\right)_{6}\right]\left(\mathrm{ClO}_{4}\right)_{3}$
}

\author{
Edward Mikulia ${ }^{\mathrm{a}}$ Natalia Górska ${ }^{\mathrm{a}}$, Stanisław Wróbel ${ }^{\mathrm{b}}$, Jacek Ściesińskic \\ and Ewa Ściesińska ${ }^{\mathrm{c}}$ \\ a Jagiellonian University, Faculty of Chemistry, Department of Chemical Physics, Ingardena 3, \\ 30-060 Kraków, Poland \\ b Jagiellonian University, Faculty of Physics, Astronomy and Applied Computer Science, \\ Department of Advanced Materials Engineering, Reymonta 4, 30-059 Kraków, Poland \\ ${ }^{c}$ H. Niewodniczański Institute of Nuclear Physics, Radzikowskiego 152, 31-342 Kraków, Poland \\ Reprint requests to Dr. hab. E. M.; Fax: +48 12634 0515; E-mail: mikuli@chemia.uj.edu.pl
}

Z. Naturforsch. 62a, 179 - 186 (2007); received March 5, 2007

A phase transition in $\left[\mathrm{Cr}\left(\mathrm{NH}_{3}\right)_{6}\right]\left(\mathrm{ClO}_{4}\right)_{3}$ at $T_{\mathrm{c}}^{\mathrm{h}}=293.5 \mathrm{~K}$ (on heating) and $T_{\mathrm{c}}^{\mathrm{c}}=293.0 \mathrm{~K}$ (on cooling) was determined by differential scanning calorimetry. The temperature dependences of the full width at half maximum of the bands connected with $\rho_{\mathrm{r}}\left(\mathrm{NH}_{3}\right) \mathrm{F}_{1 \mathrm{u}}$ and $\delta_{\mathrm{d}}(\mathrm{ClO}) \mathrm{E}$ modes suggest that the discovered phase transition is not connected with drastic changes in the speed of reorientational motions of the $\mathrm{NH}_{3}$ ligands nor the $\mathrm{ClO}_{4}{ }^{-}$anions. Temperature dependence of the FT-FIR spectra and the diffraction patterns show that the discovered phase transition is caused by a change in the crystal structure.

Key words: Hexaamminechromium(III) chlorate(VII); Phase Transition; Structural Change; DSC; FT-IR.

\section{Introduction}

The hexaamminechromium(III) chlorate(VII) crystallizes at room temperature in a cubic system (space group No. 225, $F m \overline{3} m, O_{h}^{5}$ ), with four molecules per unit cell and the lattice parameter $a=11.545 \AA$ [1]. The crystal structure consists of octahedral cations and tetrahedral anions. So far, for hexaamminemetal(III) complexes the phase transitions of $\left[\mathrm{Co}\left(\mathrm{NH}_{3}\right)_{6}\right] \mathrm{X}_{3}$, where $\mathrm{X}=\mathrm{I}^{-}, \mathrm{BF}_{4}{ }^{-}, \mathrm{ClO}_{4}{ }^{-}$and $\left[\mathrm{Cr}\left(\mathrm{NH}_{3}\right)_{6}\right]\left(\mathrm{BF}_{4}\right)_{3}$ were reported [2-5].

The aim of this study is to detect the phase transition of $\left[\mathrm{Cr}\left(\mathrm{NH}_{3}\right)_{6}\right]\left(\mathrm{ClO}_{4}\right)_{3}$ by differential scanning calorimetry (DSC) and to find a connection between the discovered phase transition and a change of the reorientational dynamics of the $\mathrm{NH}_{3}$ ligands or/and $\mathrm{ClO}_{4}{ }^{-}$groups or/and a change of the crystal structure of the title compound by Fourier transform far- and middle-infrared (FT-FIR, FT-MIR), X-ray powder and single crystal diffraction methods.

\section{Experimental}

The compound under study was obtained by adding a diluted aqueous solution of $\mathrm{HClO}_{4}$ to an aqueous so- lution of $\left[\mathrm{Cr}\left(\mathrm{NH}_{3}\right)_{6}\right] \mathrm{Cl}_{3}$, which was earlier prepared by the reaction of anhydrous $\mathrm{CrCl}_{3}$ with liquid ammonia. The obtained small, orange coloured crystals were precipitated, washed first with cold distilled water and next with diluted perchloric acid. The crystals were dried in a desiccator over $\mathrm{BaO}$ in a dark container. Before the measurements, the composition of the studied compound was determined on the basis of the ammonia content using elementary analysis on an EURO EA 3000 instrument. The elementary analysis confirmed the proper composition of the investigated compound. The average percent contents of ammonia were found to be equal to the theoretical percent value within an error limit of ca. $0.3 \%$. In order to further identify the synthesized compound and certify its purity, X-ray powder diffraction (XRPD) measurement was performed with a Seifert XRD-7 diffractometer, using Ni-filtered $\mathrm{CuK}_{\alpha}$ radiation. The space group and number of molecules are the same as those proposed by Wyckoff [1]. Additionally, the FT-RS and FT-IR spectra obtained at room temperature, described in Section 3 , certified the proper composition of the investigated substance.

The DSC measurements at 95-300 K were performed with a Perkin-Elmer PYRIS 1 DSC instrument. 
The powdered sample was placed in an aluminium vessel and was closed by compression. Another empty vessel was used for comparison. The instrument was calibrated by means of the melting points of indium and water for the high and the low temperature region, respectively. High purity dry helium $(99.999 \%)$ was used as the purging gas. As the air shield gas, nitrogen (99.999\%) was used. The nitrogen gas used for transfer of liquid nitrogen to the "cold finger" dewar was of high purity as well. Two characteristic temperatures of the DSC peaks, obtained on heating, were computed: the temperature of the peak maximum $\left(T_{\text {peak }}\right)$ and the temperature calculated from the slope of the left-hand side of the peak $\left(T_{\text {onset }}\right)$. The difference between these two temperatures ranged usually from 2 to $6 \mathrm{~K}$. The enthalpy changes $(\Delta H)$ linked up with observed transitions were calculated by numerical integration of the DSC curves under the peaks of the anomalies. A linear background was subtracted prior to the calculations. It was done in an arbitrary manner, however for every sample the procedure was the same. The entropy changes $(\Delta S)$ were calculated using the formula $\Delta S=\Delta H / T_{\mathrm{c}}$. The sharp peaks of the DSC curves were computed with high accuracy reaching $\pm 4 \%$, whereas diffuse peaks could be regarded as mere estimates.

FT-FIR and FT-MIR absorption measurements were performed using a Digilab FTS-14 and a Bruker EQUINOX-55 spectrometer, respectively. The temperature FT-FIR measurements were performed in the frequency range of $40-500 \mathrm{~cm}^{-1}$ with a resolution of $2 \mathrm{~cm}^{-1}$. The spectra of a powdered sample suspended in apiezon grease were recorded behind polyethylene and silicon windows. The FT-MIR spectra of the title compound at room temperature were recorded in the frequency range of $400-4000 \mathrm{~cm}^{-1}$, both for a sample in Nujol mulls and in a $\mathrm{KBr}$ pellet, with a resolution of $2 \mathrm{~cm}^{-1}$. The temperature measurements of FT-MIR spectra were performed in the frequency range of $500-4000 \mathrm{~cm}^{-1}$, also with a resolution of $2 \mathrm{~cm}^{-1}$ for a powdered sample suspended in a $\mathrm{KBr}$ pellet. In order to obtain FT-FIR and FT-MIR spectra at different temperatures, helium cryostats with controlled heating and cooling rates and temperature stabilization within $0.2 \mathrm{~K}$ were used. In both cases the temperature of the "cold finger" was measured with an accuracy of $\pm 1 \mathrm{~K}$, but the temperature of the sample could be by several Kelvin higher.

Fourier transform Raman scattering measurements (FT-RS) were performed at room temperature with a Bio-Rad spectrometer, with a resolution of $4 \mathrm{~cm}^{-1}$.
Table 1 . Thermodynamic parameters of the phase transition of $\left[\mathrm{Cr}\left(\mathrm{NH}_{3}\right)_{6}\right]\left(\mathrm{ClO}_{4}\right)_{3}$.

\begin{tabular}{llcc}
\hline & & Heating & Cooling \\
\hline$T_{\mathrm{c}}$ & {$[\mathrm{K}]$} & 293.5 & 293.0 \\
$\Delta H$ & {$\left[\mathrm{~kJ} \mathrm{~mol}^{-1}\right]$} & 1.21 & 1.28 \\
$\Delta S$ & {$\left[\mathrm{~J} \mathrm{~mol}^{-1} \mathrm{~K}^{-1}\right]$} & 4.1 & 4.4 \\
\hline
\end{tabular}

The incident radiation $(\lambda=1064 \mathrm{~nm})$ was from the neodymium laser YAG of Spectra-Physics.

The X-ray powder diffraction measurements at $310 \mathrm{~K}$ and $180 \mathrm{~K}$ were collected on a Philips X'Pert (PW1710) powder diffractometer, using graphite monochromatized $\mathrm{CuK}_{\alpha}$ radiation. The diffraction patterns were collected in the $2 \theta$ range of $5-80^{\circ}$, with a scan step of $0.02^{\circ}$ and a step time of $10 \mathrm{~s}$. For low temperature measurements an Anton Paar TTK 2-HC camera was used. The experimental details were the same as published in [6].

Single crystal X-ray diffraction measurements at $310 \mathrm{~K}$ and $200 \mathrm{~K}$ were also performed. A Nonius Kappa CCD diffractometer equipped with a molybdenum X-ray tube and Oxford Cryostream cooler were used. The diffraction patterns were collected in the theta range of $1.00-27.50^{\circ}$ and in the resolution range of $20.40-0.77 \AA$. The temperature data before and after the phase transition were collected in the same strategy. In order to check the stability of the $\left[\mathrm{Cr}\left(\mathrm{NH}_{3}\right)_{6}\right]\left(\mathrm{ClO}_{4}\right)_{3}$ sample after the measurements at low temperature, both the powder diffraction and single crystal diffraction pattern at $310 \mathrm{~K}$ were once more registered.

\section{Results and Discussion}

The DSC measurements were made both by heating and cooling the samples at constant rates of: 10, 20, 30 and $40 \mathrm{~K} \mathrm{~min}^{-1}$. Figure 1 shows two temperature dependencies of the heat flow (two DSC curves) obtained on heating and cooling of the $\left[\mathrm{Cr}\left(\mathrm{NH}_{3}\right)_{6}\right]\left(\mathrm{ClO}_{4}\right)_{3}$ sample at the scanning rate of $20 \mathrm{~K} \mathrm{~min}^{-1}$. One anomaly on each of these DSC curves was registered at $T_{\text {peak }}^{\mathrm{h}}=$ $294.2 \mathrm{~K}$ (on heating) and at $T_{\text {peak }}^{\mathrm{c}}=292.3 \mathrm{~K}$ (on cooling). The temperatures of the phase transition $T_{\mathrm{c}}^{\mathrm{h}}=$ $293.5 \mathrm{~K}$ and $T_{\mathrm{c}}^{\mathrm{c}}=293.0 \mathrm{~K}$ were obtained by linear extrapolation of the $T_{\text {peak }}^{\mathrm{h}}$ and $T_{\text {peak }}^{\mathrm{c}}$ values versus scanning rate of heating and cooling the sample to zero, respectively. Practical lack of thermal hysteresis and shape of the anomaly suggest second-order character of this phase transition. The thermodynamic parameters of the detected phase transition are presented in Table 1. 


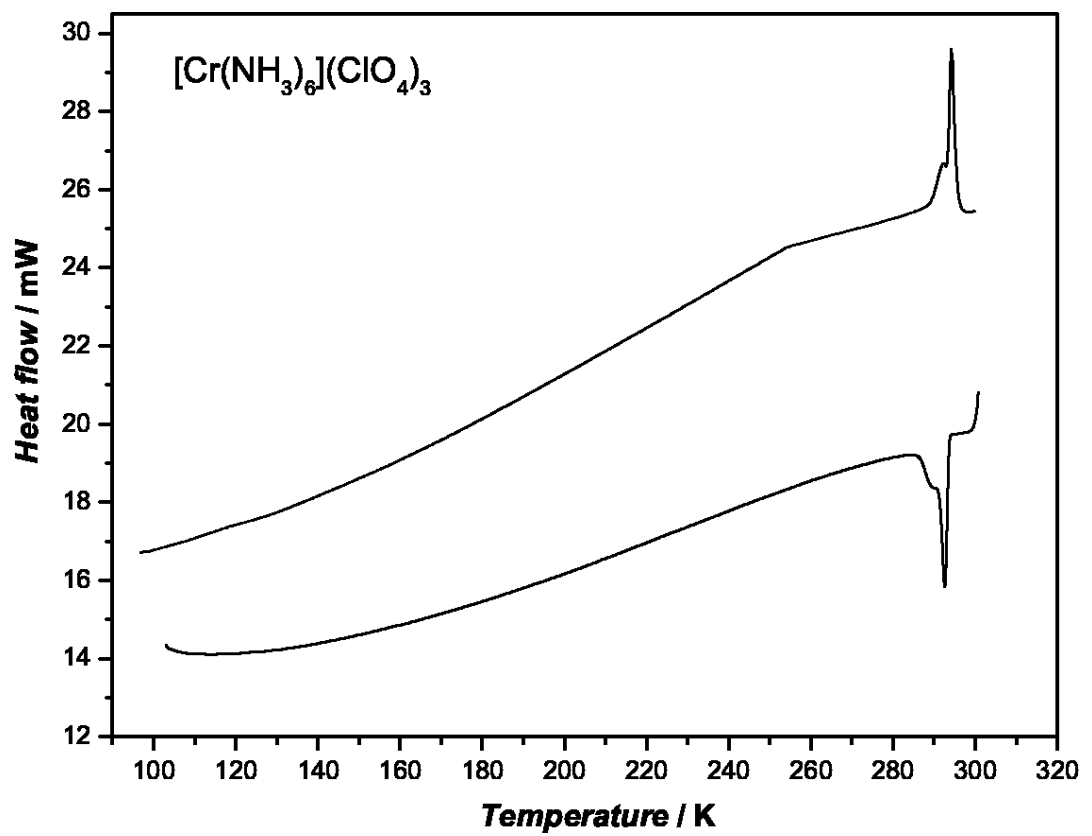

Fig. 1. DSC curves registered on heating and cooling of the $\left[\mathrm{Cr}\left(\mathrm{NH}_{3}\right)_{6}\right]\left(\mathrm{ClO}_{4}\right)_{3}$ sample at a rate of $20 \mathrm{~K} / \mathrm{min}$.

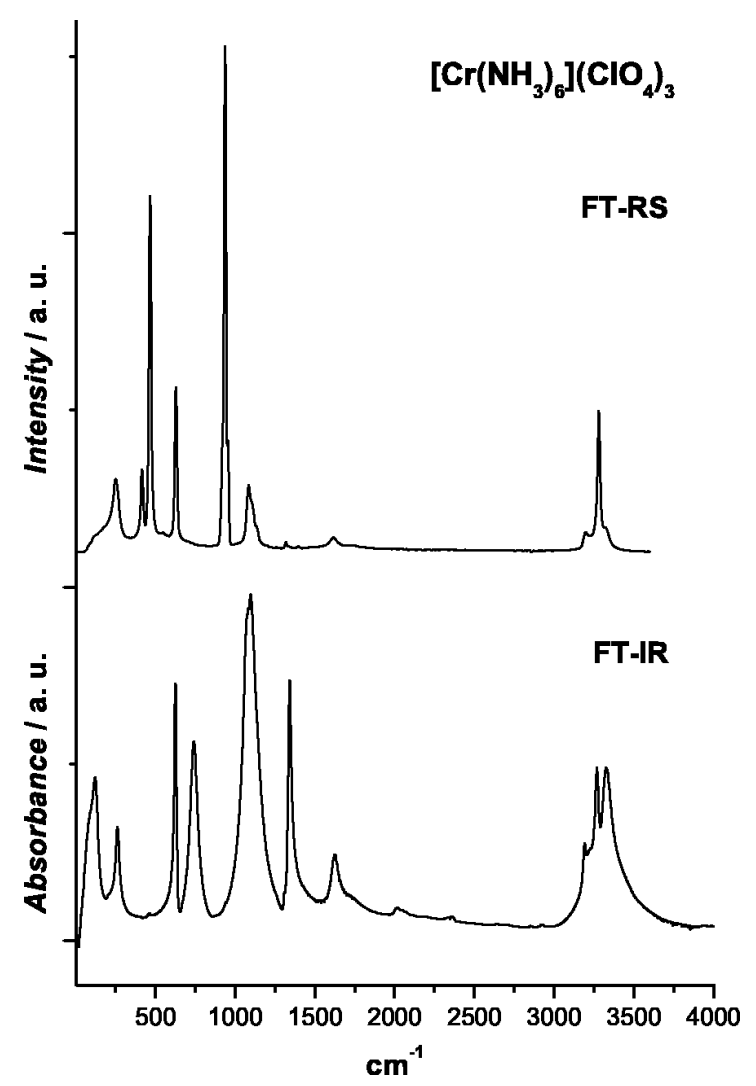

Fig. 2. Comparison of the room temperature Raman and infrared spectra of $\left[\mathrm{Cr}\left(\mathrm{NH}_{3}\right)_{6}\right]\left(\mathrm{ClO}_{4}\right)_{3}$.
Table 2. List of band positions of the Raman and infrared spectra of $\left[\mathrm{Cr}\left(\mathrm{NH}_{3}\right)_{6}\right]\left(\mathrm{ClO}_{4}\right)_{3}$ at room temperature (vw, very weak; w, weak; sh, shoulder; m, medium; st, strong; vst, very strong; br, broad) and comparison with literature data.

\begin{tabular}{|c|c|c|c|c|c|c|}
\hline \multirow{3}{*}{$\begin{array}{l}\text { RS } \\
\text { This work }\end{array}$} & \multicolumn{4}{|c|}{ Frequencies $\left[\mathrm{cm}^{-1}\right]$} & \multirow[b]{3}{*}[10]{} & \multirow{3}{*}{ Assignments } \\
\hline & \multicolumn{4}{|c|}{ IR } & & \\
\hline & & & [8] & [9] & & \\
\hline$\sim 3324 \mathrm{sh}$ & & & & & & $v_{\text {as }}(\mathrm{NH}) \mathrm{F}_{2 \mathrm{~g}}$ \\
\hline $3281 \mathrm{~m}$ & $3326 \mathrm{~m}$, br & & 3330 & 3328 & 3311 & $\begin{array}{l}v_{\text {as }}(\mathrm{NH}) \mathrm{F}_{1 \mathrm{u}} \\
v_{\mathrm{s}}(\mathrm{NH}) \mathrm{A}_{1 \mathrm{~g}}\end{array}$ \\
\hline & $3268 \mathrm{~m}$ & & 3280 & 3270 & & $v_{\mathrm{s}}(\mathrm{NH}) \mathrm{F}_{1 \mathrm{u}}$ \\
\hline & $3191 \mathrm{w}$ & & & 3192 & & $2 \delta_{\mathrm{as}}(\mathrm{HNH}) \mathrm{F}_{1 \mathrm{u}}$ \\
\hline $3197 \mathrm{sh}$ & & & & & & $v_{\mathrm{s}}(\mathrm{NH}) \mathrm{E}_{\mathrm{g}}$ \\
\hline $\begin{array}{l}1615 \mathrm{w} \\
1396 \mathrm{vw}\end{array}$ & $1625 \mathrm{~m}$ & & 1622 & 1620 & 1614 & $\begin{array}{l}\delta_{\mathrm{as}}(\mathrm{HNH}) \mathrm{F}_{1 \mathrm{u}} \\
\delta_{\mathrm{as}}(\mathrm{HNH}) \mathrm{F}_{2 \mathrm{~g}} \\
\delta_{\mathrm{s}}(\mathrm{HNH}) \mathrm{A}_{1 \mathrm{~g}}\end{array}$ \\
\hline $1317 \mathrm{vw}$ & $1342 \mathrm{st}$ & & 1334 & 1330 & 1339 & $\begin{array}{l}\delta_{\mathrm{s}}(\mathrm{HNH}) \mathrm{A}_{1 \mathrm{~g}} \\
\delta_{\mathrm{s}}(\mathrm{HNH}) \mathrm{F}_{1 \mathrm{u}} \\
\delta_{\mathrm{s}}(\mathrm{HNH}) \mathrm{E}_{\mathrm{s}}\end{array}$ \\
\hline$\sim 1136 \mathrm{sh}$ & & & & & & $\begin{array}{l}O_{\mathrm{s}}(\mathrm{MNH}) \mathrm{E}_{\mathrm{g}} \\
v_{\mathrm{as}}(\mathrm{ClO}) \mathrm{F}_{2}\end{array}$ \\
\hline$\sim 1110 \mathrm{sh}$ & & & & & & $v_{\mathrm{as}}(\mathrm{ClO}) \mathrm{F}_{2}$ \\
\hline $\begin{array}{r}1084 \mathrm{~m} \\
955 \mathrm{sh} \\
937 \mathrm{vst}\end{array}$ & 1098 vst & & & & & $\begin{array}{l}v_{\text {as }}(\mathrm{ClO}) \mathrm{F}_{2} \\
2 \delta_{\mathrm{d}}(\mathrm{OClO}) \mathrm{E}\end{array}$ \\
\hline 937 vst & $741 \mathrm{st}$ & & 718 & 742 & 743 & $v_{\mathrm{s}}(\mathrm{ClO}) \mathrm{A}_{1}$ \\
\hline $629 \mathrm{st}$ & $\begin{array}{l}741 \mathrm{st} \\
625 \mathrm{vst}\end{array}$ & & 110 & & 143 & $\begin{array}{l}\rho_{\mathrm{r}}\left(\mathrm{NH}_{3}\right) \mathrm{F}_{1 \mathrm{u}} \\
\delta_{\mathrm{d}}(\mathrm{OClO}) \mathrm{F}_{2}\end{array}$ \\
\hline $548 \mathrm{vw}$ & & & & & & $v(\mathrm{CrN}) \mathrm{A}_{1 \mathrm{~g}}$ \\
\hline $\begin{array}{l}467 \text { vst } \\
417 \mathrm{~m}\end{array}$ & $460 \mathrm{vw}$ & $460 \mathrm{w}$ & & 456 & & $\delta_{\mathrm{d}}(\mathrm{OClO}) \mathrm{E}$ \\
\hline $\begin{array}{l}417 \mathrm{~m} \\
251 \mathrm{~m}\end{array}$ & $261 \mathrm{~m}$ & $261 \mathrm{st}$ & & & & $\begin{array}{l}v(\mathrm{CrN}) \mathrm{E}_{\mathrm{g}} \\
\delta_{\mathrm{as}}(\mathrm{NCrN}) \mathrm{F}_{1 \mathrm{u}} \\
\delta_{\mathrm{as}}(\mathrm{NCrN}) \mathrm{F}_{2 \mathrm{~g}}\end{array}$ \\
\hline & $121 \mathrm{~m}$ & & & & & $v_{\mathrm{L}}($ lattice $) \mathrm{F}_{1 \mathrm{u}}$ \\
\hline
\end{tabular}

Figure 2 shows a comparison of Raman and infrared spectra of $\left[\mathrm{Cr}\left(\mathrm{NH}_{3}\right)_{6}\right]\left(\mathrm{ClO}_{4}\right)_{3}$ obtained at room tem- 

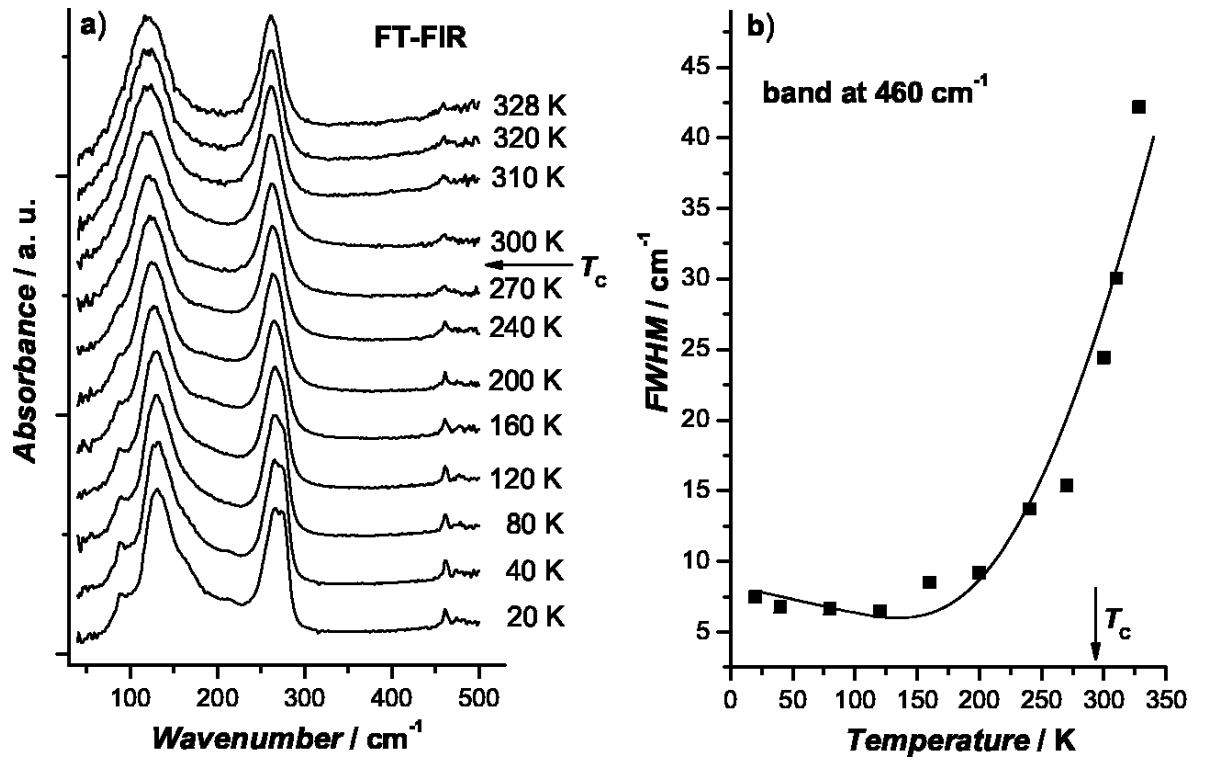

Fig. 3. (a) Temperature evolution of the FT-FIR spectra of $\quad\left[\mathrm{Cr}\left(\mathrm{NH}_{3}\right)_{6}\right]\left(\mathrm{ClO}_{4}\right)_{3}$. (b) Temperature dependence of the FWHM of the band at $460 \mathrm{~cm}^{-1}$ connected with the $\delta_{\mathrm{d}}(\mathrm{OClO}) \mathrm{E}$ mode. perature. There are 63 normal modes for the complex cation: $3 \mathrm{~A}_{1 \mathrm{~g}}+3 \mathrm{E}_{\mathrm{g}}+3 \mathrm{~F}_{1 \mathrm{~g}}+7 \mathrm{~F}_{1 \mathrm{u}}+4 \mathrm{~F}_{2 \mathrm{~g}}+4 \mathrm{~F}_{2 \mathrm{u}}$, but $3 \mathrm{~F}_{1 \mathrm{~g}}$ and $4 \mathrm{~F}_{2 \mathrm{u}}$ are Raman and infrared inactive, respectively. Rotation of the $\mathrm{NH}_{3}$ groups about the $\mathrm{Cr}-\mathrm{N}$ bonds takes 6 degrees of freedom. The $\mathrm{ClO}_{4}{ }^{-}$anion has 9 normal modes: $\mathrm{A}_{1}, \mathrm{E}$ and $2 \mathrm{~F}_{2}$. Two first are infrared inactive but all of them are active in the Raman spectrum. The cation was considered to have octahedral symmetry with freely rotating ammine groups and the anion has tetrahedral symmetry. Table 2 presents a list of the band positions, observed in the RS and IR spectra of $\left[\mathrm{Cr}\left(\mathrm{NH}_{3}\right)_{6}\right]\left(\mathrm{ClO}_{4}\right)_{3}$, their relative intensities and assignments denoted by comparing with the literature data $[7-16]$ for several $\left[\mathrm{M}\left(\mathrm{NH}_{3}\right)_{6}\right] \mathrm{X}_{3}$ complexes. These assignments proved that both the composition and the structure of the investigated compound are as expected.

Figure 3a shows FT-FIR spectra of the studied compound in the wavenumber range of $40-500 \mathrm{~cm}^{-1}$ registered on cooling the sample from 328 to $20 \mathrm{~K}$. The spectrum at room temperature contains three bands: at $121 \mathrm{~cm}^{-1}$, connected with the $v_{\mathrm{L}}$ lattice vibration mode, $261 \mathrm{~cm}^{-1}$, connected with the $\delta_{\mathrm{as}}(\mathrm{NCrN}) \mathrm{F}_{1 \mathrm{u}}$ mode of internal vibration of the octahedral cation. The third very weak band can also be observed at $460 \mathrm{~cm}^{-1}$. It is connected with the $\delta_{\mathrm{d}}(\mathrm{OClO}) \mathrm{E}$ mode of the $\mathrm{ClO}_{4}^{-}$anion. Some small but characteristic changes can be observed between the FT-FIR spectra. In the low temperature phase (below the phase transition) a new, small band appears at about $90 \mathrm{~cm}^{-1}$ and the intensity of the room temperature very weak band at $460 \mathrm{~cm}^{-1}$ increased as the temperature decreased. This apearing of the band at $460 \mathrm{~cm}^{-1}$, which is forbidden in the high symmetry phase, and the new band at $90 \mathrm{~cm}^{-1}$ can suggest that the symmetry of the crystal decreases during cooling.

In order to check if the recorded phase transition in $\left[\mathrm{Cr}\left(\mathrm{NH}_{3}\right)_{6}\right]\left(\mathrm{ClO}_{4}\right)_{3}$ is connected with a change in the reorientational dynamics of the $\mathrm{NH}_{3}$ groups and/or $\mathrm{ClO}_{4}{ }^{-}$anions, we follow the analysis of FWHM described by Carabatos-Nédelec and Becker [17], which is based on the theory used for the damping associated with an order-disorder mechanism. The orientational correlation time $\tau_{\mathrm{R}}$ is the mean time between the instantaneous jumps from one potential well to another and it is given by

$$
\tau_{\mathrm{R}}=\tau_{\infty} \cdot \exp \left(\frac{E_{\mathrm{a}}}{R T}\right)
$$

where $\tau_{\infty}$ is the relaxation time at infinite temperature $T$ and $E_{\mathrm{a}}$ is the height of the potential barrier for the $\mathrm{NH}_{3}$ or $\mathrm{ClO}_{4}^{-}$groups.

When $\varpi^{2} \cdot \tau_{\mathrm{R}}{ }^{2} \gg 1$, the temperature dependence of the band width at half maximum (FWHM) is described by [18]

$$
\operatorname{FWHM}(T)=(a+b T)+c \cdot \exp \left(-\frac{E_{\mathrm{a}}}{R T}\right),
$$

where $\varpi$ is the frequency of a particular phonon mode and $a, b, c, E_{\mathrm{a}}$ are parameters to fit. The linear part 


\section{$\left[\mathrm{Cr}\left(\mathrm{NH}_{3}\right)_{6}\right](\mathrm{ClO})_{3}$}

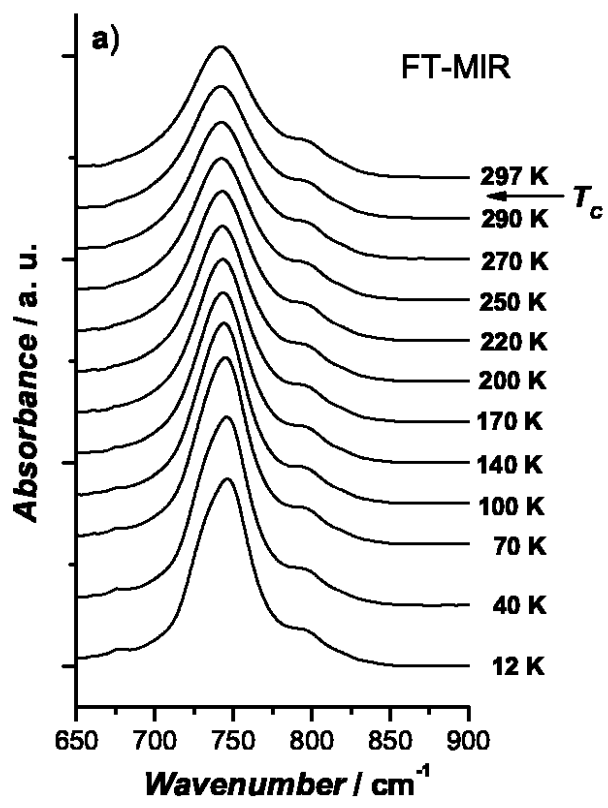

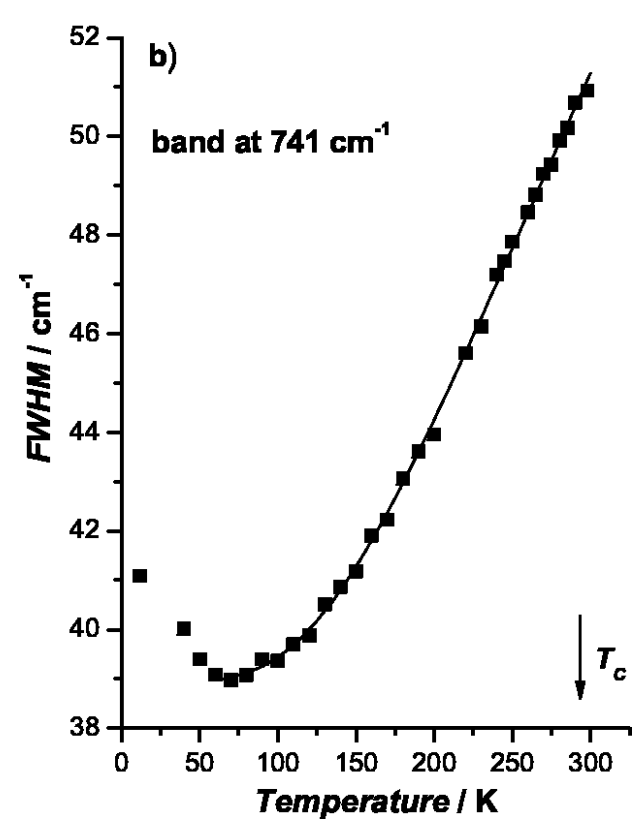

Fig. 4. (a) Temperature evolution of the band at $741 \mathrm{~cm}^{-1}$ connected with the $\rho_{\mathrm{r}}\left(\mathrm{NH}_{3}\right) \mathrm{F}_{1 \mathrm{u}}$ mode. (b) Temperature dependence of the FWHM of this band.
Table 3. The fitted parameters $a, b, c$ and $E_{\mathrm{a}}$, for the temperature dependence of the full width at half maximum (FWHM) of the band at $460 \mathrm{~cm}^{-1}$, connected with the $\delta_{\mathrm{d}}(\mathrm{OClO}) \mathrm{E}$ mode, and at $741 \mathrm{~cm}^{-1}$, connected with the $\rho_{\mathrm{r}}\left(\mathrm{NH}_{3}\right) \mathrm{F}_{1 \mathrm{u}}$ mode.

\begin{tabular}{lll}
\hline Parameter & Band at $460 \mathrm{~cm}^{-1}$ & Band at $741 \mathrm{~cm}^{-1}$ \\
\hline$a\left[\mathrm{~cm}^{-1}\right]$ & 8.3 & 38.8 \\
$b\left[\mathrm{~cm}^{-1} \mathrm{~K}^{-1}\right]$ & $-2.0 \cdot 10^{-2}$ & $2.7 \cdot 10^{-3}$ \\
$c\left[\mathrm{~cm}^{-1}\right]$ & 871.1 & 65.8 \\
$E_{\mathrm{a}}\left[\mathrm{kJ} \mathrm{mol}^{-1}\right]$ & 8.8 & 4.3 \\
\hline
\end{tabular}

of (2) corresponds to the vibrational relaxation, and the exponential term corresponds to the thermal orientational mechanism of diffuse nature.

The FWHM of the bands connected with $\delta_{\mathrm{d}}(\mathrm{ClO}) \mathrm{E}$ and $\rho_{\mathrm{r}}\left(\mathrm{NH}_{3}\right) \mathrm{F}_{1 \mathrm{u}}$ modes for different temperatures of the FT-FIR and FT-MIR measurements were calculated by fitting to it the Lorentz function using GRAMS 32 v5.2 procedure. Figure $3 b$ presents the temperature dependence of the FWHM of the band connected with the $\delta_{\mathrm{d}}(\mathrm{ClO}) \mathrm{E}$ mode. The solid line is fitted by (2), and the fitted parameters for both investigated bands are listed in Table 3. As can be seen, the FWHM value decreases exponentially while the temperature is lowered. There are no drastic changes of the FWHM in the phase transition temperature region which implies that the phase transition observed in $\left[\mathrm{Cr}\left(\mathrm{NH}_{3}\right)_{6}\right]\left(\mathrm{ClO}_{4}\right)_{3}$ is not connected with a rapid change in the speed of reorientational motions of the $\mathrm{ClO}_{4}{ }^{-}$anions. The mean value of the activation energy for reorientation of the $\mathrm{ClO}_{4}{ }^{-}$anions is $E_{\mathrm{a}}=$ $8.8 \mathrm{~kJ} \mathrm{~mol}^{-1}$. It is somewhat larger than that for reorientation of $\mathrm{BF}_{4}^{-}$ions $\left(E_{\mathrm{a}}=7.9 \mathrm{~kJ} \mathrm{~mol}^{-1}\right)$ estimated for $\left[\mathrm{Cr}\left(\mathrm{NH}_{3}\right)_{6}\right]\left(\mathrm{BF}_{4}\right)_{3}[19]$.

Figures $4 \mathrm{a}$ and $\mathrm{b}$ present the temperature evolution of the band connected with the rocking mode $\rho_{\mathrm{r}}\left(\mathrm{NH}_{3}\right) \mathrm{F}_{1 \mathrm{u}}$ of internal $\mathrm{NH}_{3}$ vibration in $\left[\mathrm{Cr}\left(\mathrm{NH}_{3}\right)_{6}\right]\left(\mathrm{ClO}_{4}\right)_{3}$ and the dependence of the FWHM for this band, respectively. The FWHM value calculated for this mode decreases exponentially while the temperature is being reduced till about $80 \mathrm{~K}$. Below this temperature the FWHM starts to grow. No drastic changes of the FWHM value are observed at the vicinity of the phase transition temperature. This means that the fast (the correlation time is of the order of picoseconds) reorientation of the $\mathrm{NH}_{3}$ ligands does not drastically change in the temperature region of the detected phase transition. The value of the activation energy for the reorientation of the ammonia ligands calculated according to (2) amounts to $4.3 \mathrm{~kJ} \mathrm{~mol}^{-1}$ (Table 3 ). The mean value is very close to those estimated for similar compounds: $\left[\mathrm{Co}\left(\mathrm{NH}_{3}\right)_{6}\right]\left(\mathrm{ClO}_{4}\right)_{3}\left(4.5 \mathrm{~kJ} \mathrm{~mol}^{-1}\right)$ and $\left[\mathrm{Co}\left(\mathrm{NH}_{3}\right)_{6}\right] \mathrm{J}_{3}\left(4.9 \mathrm{~kJ} \mathrm{~mol}^{-1}\right)[3,5]$.

The X-ray powder diffraction pattern was recorded at room temperature for the compound under study 


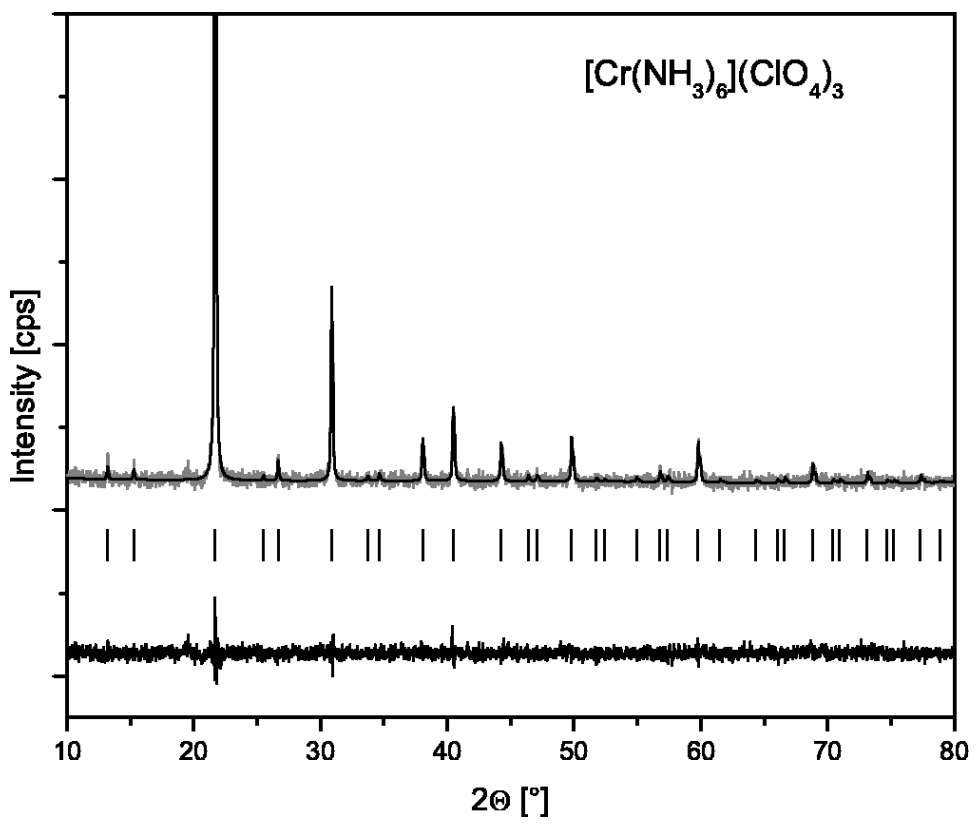

Fig. 5. Calculated (black curve), observed (grey curve) and difference (lower curve) profiles and calculated peak positions $(\mid)$ of $\left[\mathrm{Cr}\left(\mathrm{NH}_{3}\right)_{6}\right]\left(\mathrm{ClO}_{4}\right)_{3}$ at room temperature. in order to compare the crystal data obtained for our sample with data known from the literature and to additionally prove the purity of our sample. During the measurement, the sample was protected against decomposition by Nujol. The diffraction pattern obtained at room temperature was indexed in a regular system with the lattice parameter $a=11.571(18) \AA$ and four formula units in the unit cell using the PROSZKI system [20]. All the observed reflections could be indexed. The space group No. $225\left(F m \overline{3} m, O_{\mathrm{h}}^{5}\right)$ was found by a systematic absences analysis. We performed a LeBail fit to the measured profile, using the program JANA2000 [21]. The high symmetry of the lattice is possible because the $\mathrm{NH}_{3}$ ligands and $\mathrm{ClO}_{4}{ }^{-}$anions perform very fast (picosecond time scale) reorientational motions. Figure 5 shows the measured (gray curve) and calculated (black curve) powder diffraction profiles, calculated peak positions and the difference curve between the measured and calculated profile in room temperature.

In order to check if the recorded phase transition is connected with a change of the crystal structure of $\left[\mathrm{Cr}\left(\mathrm{NH}_{3}\right)_{6}\right]\left(\mathrm{ClO}_{4}\right)_{3}$, the X-ray powder diffraction patterns at 310 and $180 \mathrm{~K}$ were obtained, as is presented in Figure 6. In the diffraction pattern obtained at $180 \mathrm{~K}$ many new reflections appeared which suggest the structural character of the studied phase transition. Most of them have a rather weak intensity. Unfortunately, in the low temperature phase not all of the ob-
Table 4. Crystallographic data, atomic coordinates $\left(\cdot 10^{4}\right)$ and equivalent isotropic displacement parameters $\left(\AA^{2} \cdot 10^{3}\right)$ for cramon. $U(\mathrm{eq})$ is defined as one third of the trace of the orthogonalized $U^{i j}$ tensor.

\begin{tabular}{|c|c|c|c|c|}
\hline \multicolumn{3}{|c|}{$\overline{\text { Identification code }}$} & \multicolumn{2}{|c|}{ cramon } \\
\hline \multicolumn{3}{|c|}{ Temperature } & \multicolumn{2}{|c|}{$310.0(1) \mathrm{K}$} \\
\hline \multicolumn{3}{|c|}{ Crystal system (space group) } & \multicolumn{2}{|c|}{ cubic $(F m \overline{3} m)$} \\
\hline \multicolumn{3}{|c|}{ Unit cell dimensions } & \multicolumn{2}{|c|}{$a=11.572(5) \AA$} \\
\hline \multicolumn{3}{|l|}{$Z$} & \multicolumn{2}{|c|}{4} \\
\hline \multicolumn{3}{|c|}{$F(000)$} & \multicolumn{2}{|c|}{924} \\
\hline \multicolumn{3}{|c|}{ Reflections collected } & \multicolumn{2}{|c|}{4920} \\
\hline \multicolumn{3}{|c|}{ Refinement method } & \multicolumn{2}{|c|}{ Full-matrix least-squares on $F^{2}$} \\
\hline \multicolumn{3}{|c|}{ Goodness-of-fit on $F^{2}$} & \multicolumn{2}{|c|}{1.133} \\
\hline \multicolumn{3}{|c|}{$R$ indices } & \multicolumn{2}{|c|}{$R 1=0.0369, w R 2=0.0858$} \\
\hline Atom & $x$ & $y$ & $z$ & $U$ \\
\hline$\overline{\mathrm{Cr}}$ & 0 & 0 & 0 & $23(1)$ \\
\hline $\mathrm{N}$ & 0 & 0 & $-1792(2)$ & $40(1)$ \\
\hline $\mathrm{Cl1}$ & 2500 & -2500 & -2500 & $45(1)$ \\
\hline $\mathrm{Cl} 2$ & 0 & 0 & -5000 & $29(1)$ \\
\hline $\mathrm{O} 1 \mathrm{~A}$ & 2500 & $-1172(6)$ & -2500 & $66(2)$ \\
\hline O1B & $3172(4)$ & $-1828(4)$ & $-3172(4)$ & $75(2)$ \\
\hline $\mathrm{O} 1 \mathrm{C}$ & $1940(20)$ & $-1940(20$ & $-3060(20)$ & $220(20)$ \\
\hline $\mathrm{O} 2 \mathrm{~A}$ & $-719(2)$ & $719(2)$ & $-4281(2)$ & $47(1)$ \\
\hline \multirow{5}{*}{\multicolumn{2}{|c|}{ Distances $[\AA]$}} & $\mathrm{Cr}-\mathrm{N}$ & $2.074(3)$ & \\
\hline & & C11-O1A & $1.537(7)$ & \\
\hline & & Cl1-O1B & $1.346(8)$ & \\
\hline & & Cl1-O1C & $1.12(5)$ & \\
\hline & & $\mathrm{Cl} 2-\mathrm{O} 2 \mathrm{~A}$ & $1.441(5)$ & \\
\hline
\end{tabular}

served reflections could be indexed in any crystal system. Also, the X-ray single crystal diffraction patterns were obtained for this compound at 310 and $200 \mathrm{~K}$ (Fig. 7). The details of this measurement, coordinates 

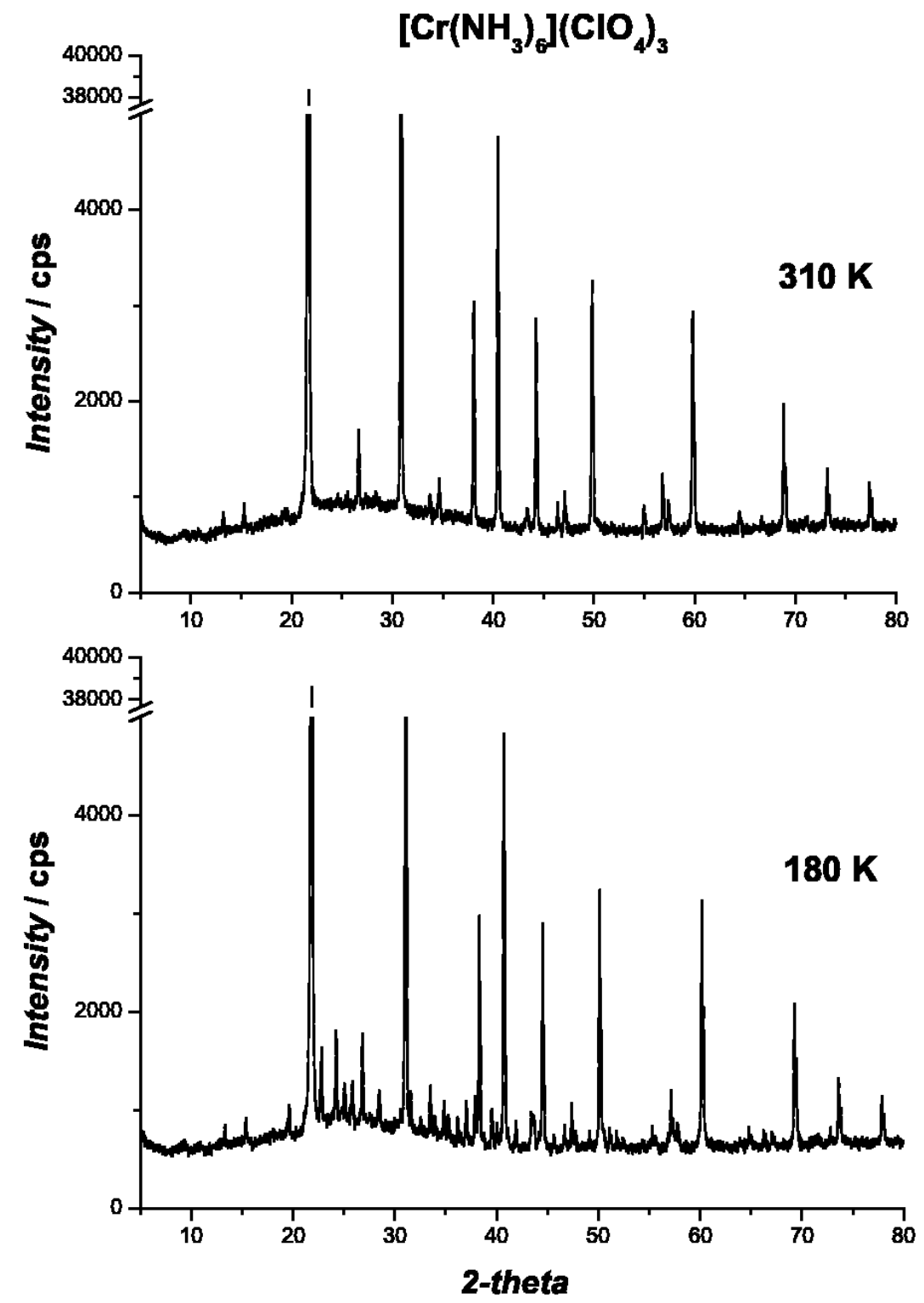

Fig. 6. The powder diffraction patterns registered for $\left[\mathrm{Cr}\left(\mathrm{NH}_{3}\right)_{6}\right]\left(\mathrm{ClO}_{4}\right)_{3}$ at $310 \mathrm{~K}$ and $180 \mathrm{~K}$.

a)

b)
Fig. 7. The single crystal diffraction patterns obtained for $\left[\mathrm{Cr}\left(\mathrm{NH}_{3}\right)_{6}\right]\left(\mathrm{ClO}_{4}\right)_{3}$ at: (a) $310 \mathrm{~K}$ and (b) $200 \mathrm{~K}$. 
of atoms, thermal displacement parameters and selected bond lengths for the compound under study obtained at $310 \mathrm{~K}$ are listed in Table 4 . In the diffraction patterns obtained at $200 \mathrm{~K}$ also many new reflections appeared, what is connected with a change in the crystal structure of the investigated compound (see Fig. 7b). Characteristic satellite reflections appeared beside the old ones existing in the high temperature phase. The X-ray diffraction results obtained both for a powdered and single crystal sample suggest that probably below the phase transition temperature a superstructure occurs.

\section{Conclusions}

1. The DSC measurements of $\left[\mathrm{Cr}\left(\mathrm{NH}_{3}\right)_{6}\right]\left(\mathrm{ClO}_{4}\right)_{3}$ performed at 95-298 $\mathrm{K}$ allowed a phase transition to be detected. The temperature of the phase transition, obtained by extrapolation of the $T_{\text {peak }}^{\mathrm{h}}$ and $T_{\text {peak }}^{\mathrm{c}}$ values to zero scanning rate, amounts to $T_{\mathrm{c}}^{\mathrm{h}}=293.5 \mathrm{~K}$ and $T_{\mathrm{c}}^{\mathrm{c}}=293.0 \mathrm{~K}$, respectively.

[1] R. W. G. Wyckoff, Crystal Structures, Vol. 3, Interscience, New York 1965.

[2] W. T. Ziegler, J. Am. Chem. Soc. 63, 2700 (1941).

[3] M. Goettel, J. M. Janik, J. A. Janik, and M. Rachwalska, Phys. Status Solidi (a) 35, 675 (1976).

[4] G. R. Murray and J. S. Waugh, J. Chem. Phys. 29, 207 (1958).

[5] E. Mikuli, A. Migdał-Mikuli, N. Górska, S. Wróbel, J. Ściesiński, and E. Ściesińska, J. Mol. Struct. 651 653, 519 (2003).

[6] A. Migdał-Mikuli, E. Mikuli, S. Wróbel, Ł. Hetmańczyk, I. Natkaniec, K. Hołderna-Natkaniec, and W. Łasocha, J. Solid State Chem. 174, 357 (2003).

[7] T. W. Swaddle, P. J. Craig, and P. M. Boorman, Spectrochim. Acta 26A, 1559 (1970).

[8] J. Fujita, K. Nakamoto, and M. Kobayashi, J. Am. Chem. Soc. 78, 3295 (1956).

[9] J. M. Terrasse, H. Poulet, and J.P. Mathieu, Spectrochim. Acta 20, 305 (1964).

[10] N. Tanaka, M. Kamada, J. Fujita, and E. Kyuno, Bull. Chem. Soc. Jpn. 37, 222 (1964).
2. The temperature dependences of the FWHM of the bands connected with the $\rho_{\mathrm{r}}\left(\mathrm{NH}_{3}\right) \mathrm{F}_{1 \mathrm{u}}$ and $\delta_{\mathrm{d}}(\mathrm{OClO}) \mathrm{E}$ modes suggest that the observed phase transition is most likely not caused by a change in the speed of reorientational motions neither of the $\mathrm{NH}_{3}$ ligands nor $\mathrm{ClO}_{4}{ }^{-}$anions.

3. There are some characteristic changes of the FT-FIR spectra in the phase transition temperature range, which imply that the phase transition at $T_{\mathrm{c}} \approx 293 \mathrm{~K}$ is connected with a change of the crystal structure. Distinct changes in the powder diffraction and single crystal patterns registered before and after the phase transition temperature confirm the structural character of the discovered phase transition.

\section{Acknowledgements}

We thank Dr. W. Nitek from the Jagiellonian University in Kraków for making the temperature powder and single crystal X-ray diffraction measurements for us.

[11] S. Mizushima, I. Nakagawa, and J. V. Quagliano, J. Chem. Phys. 23, 1367 (1955).

[12] D. G. Hill and A. F. Rosenberg, J. Chem. Phys. 24, 1219 (1956).

[13] H. Siebert and H. H. Eysel, J. Mol. Struct. 4, 29 (1969).

[14] A. Müller and E. J. Baran, J. Mol. Struct. 15, 283 (1973).

[15] K. H. Schmidt and A. Müller, Coord. Chem. Rev. 19, 41 (1976).

[16] R. Acevedo, G. Diaz, and C.D. Flint, Spectrochim. Acta 41A, 1397 (1985).

[17] C. Carabatos-Nédelec and P. Becker, J. Raman Spectrosc. 28, 663 (1997).

[18] G. Bator, R. Jakubas, and J. Baran, Vib. Spectrosc. 25, 101 (2001).

[19] E. Mikuli, N. Górska, S. Wróbel, J. Ściesiński, and E. Ściesińska, J. Mol. Struct. 692, 231 (2004).

[20] W. Łasocha and K. Lewiński, J. Appl. Crystallogr. 27, 437 (1994)

[21] V. Petricek and M. Dusek, Jana 2000 - the Crystallographic Computing System, Institute of Physics, Praha, Czech Republic 2000. 